\title{
Cartilage calcification of the ankle joint is associated with osteoarthritis in the general population
}

\author{
Jan Hubert ${ }^{1 *}$, Lukas Weiser ${ }^{1}$, Sandra Hischke ${ }^{2}$, Annemarie Uhlig ${ }^{3}$, Tim Rolvien ${ }^{4}$, Tobias Schmidt ${ }^{4}$, \\ Sebastian Karl Butscheidt ${ }^{4}$, Klaus Püschel ${ }^{5}$, Wolfgang Lehmann ${ }^{1}$, Frank Timo Beil ${ }^{1}$ and Thelonius Hawellek ${ }^{* *}$
}

\begin{abstract}
Background: Cartilage calcification (CC) is associated with osteoarthritis (OA) in weight-bearing joints, such as the hip and the knee. However, little is known about the impact of CC and degeneration on other weight-bearing joints, especially as it relates to the occurrence of $\mathrm{OA}$ in the ankles. The goal of this study is to analyse the prevalence of ankle joint cartilage calcification (AJ CC) and to determine its correlation with factors such as histological OA grade, age and BMI in the general population.

Methods: CC of the distal tibia and talus in 160 ankle joints obtained from 80 donors (mean age 62.4 years, 34 females, 46 males) was qualitatively and quantitatively analysed using high-resolution digital contact radiography (DCR). Correlations with factors, such as the joint's histological OA grade (OARSI score), donor's age and BMI, were investigated.

Results: The prevalence of AJ CC was 51.3\% (95\% CI [0.40, 0.63]), independent of gender $(p=0.18)$ and/or the joint's side $(p=0.82)$. CC of the distal tibia was detected in $35.0 \%(28 / 80)(95 \% \mathrm{Cl}[0.25,0.47])$ and talar CC in $47.5 \%(38 / 80)(95 \% \mathrm{Cl}[0$. $36,0.59])$ of all cases. Significant correlations were noted between the mean amount of tibial and talar CC $(r=0.59, p=0$. 002), as well as between the mean amount of CC observed in one ankle joint with that of the contralateral side $(r=0.52$, $p=0.02$ ). Furthermore, although the amount of AJ CC observed in the distal tibia and talus correlated with the histological OA-grade of the joint $(r=0.70, p<0.001$ and $r=0.72, p<0.001$, respectively), no such correlation was seen in the general population with relation to age $(p=0.32$ and $p=0.49)$ or $\operatorname{BMl}(p=0.51$ and $p=0.87)$.

Conclusion: The prevalence of AJ CC in the general population is much higher than expected. The relationship between the amount of AJ CC and OA, independent of the donors' age and BMI, indicates that CC may play a causative role in the development of $\mathrm{OA}$ in ankles.
\end{abstract}

Keywords: Cartilage calcification, Calcium crystals, Chondrocalcinosis, Ankle joint, Osteoarthritis, Cartilage

\section{Background}

Osteoarthritis $(\mathrm{OA})$ is a major health problem that affects about $15 \%$ of the global population [1]. While OA in weight-bearing hip and knee joints is relatively common, in the ankle joint (AJ) it affects only $1 \%$ of the population [2]. It is often hypothesized that the development of AJ OA is mostly related to previous trauma [3, 4]. Valderrabano et al. reported a high prevalence of post-traumatic

\footnotetext{
* Correspondence: jan.hubert@med.uni-goettingen.de;

thelonius.hawellek@med.uni-goettingen.de

'Department of Trauma Surgery, Orthopaedics and Plastic Surgery, University Medical Center Göttingen, Robert-Koch-Straße 40, 37075 Göttingen, Germany Full list of author information is available at the end of the article
}

AJ OA (in 78\% of cases) [4], while, other studies have shown a considerably lower prevalence (only 14\%) [5]. The real impact of trauma on the development of AJ OA is yet to be fully understood, and the ability to accurately predict which patients will develop AJ OA in the future requires further investigations.

It is likely that the variations in individuals' articular cartilage composition will play a role in the development of AJ OA. Eckstein et al. reported surprisingly high variability in the quantitative distribution of cartilage in the ankles of patients [6], whereas Quinn et al. found intraindividual variations in the cartilage cells and matrix morphologies of knees and ankle joints [7]. 
Another possible explanation for the development of AJ OA could be the occurrence of calcification within the hyaline articular cartilage, also known as chondrocalcinosis [8]. A high prevalence of cartilage calcification $(\mathrm{CC})$ as well as a significant correlation between $\mathrm{CC}$ and $\mathrm{OA}$ has been reported in both weight-bearing hip and knee joints as well as in the first metatarsophalangeal joint (MTP-I joint) [9-13]. Furthermore, in vitro studies have shown that calcium phosphate crystals can alter cartilage tissue via biomechanical [14, 15] and pro-inflammatory biochemical processes [16$19]$, all of which can lead to degeneration of the affected joint.

The prevalence of ankle joint cartilage calcification (AJ $\mathrm{CC})$ in the general population is reported at around $4.7 \%$, and is based on only one cross-sectional study in which the occurrence of calcification on the talar surface was analysed macroscopically [20] and an association between CC and OA of the talus was reported. However, early signs of $\mathrm{CC}$ are only measurable in the nano- to micrometre ranges, thus raising the possibility of underestimation with conventional imaging techniques. In order to detect the onset of CC, high-resolution imaging techniques like digital contact radiography (DCR) are required [21]. Taking this into account, the precision of the previously reported cross-sectional study might be called into question [20].

Therefore, the primary goal of this study was to evaluate and quantify the prevalence of $\mathrm{AJ} \mathrm{CC}$ using high-resolution DCR. Secondly, we examined the correlations between the observed $\mathrm{CC}$ with age, $\mathrm{BMI}$ and the histological grade of osteoarthritis.

\section{Methods}

Both ankle joints $(n=160)$ of 80 donors were obtained from an unselected cohort who underwent autopsy at the Department for Legal Medicine, University Medical Center Hamburg-Eppendorf [22]. Only donors with bilaterally intact ankle joints with no signs of any other diseases (except for OA) were included in this study. Donors with a history of previous ankle surgery, tumours, infections and/or rheumatic diseases were excluded. The study was approved by the local Ethics Committee (PV 4570) and is in compliance with the Helsinki Declaration.

\section{Sample preparation}

Firstly, the whole ankle joint of the right and left limbs were extracted. Next, the soft tissue was carefully removed from the talus and the distal tibia along with the corresponding tibiofibular joint. For the calcification analysis, standardized $4 \mathrm{~mm}$ cartilage-bone specimens were cut in the coronal plane of the talus and the distal tibia along with the corresponding tibiofibular joint (Fig. 1).

\section{Digital contact radiography (DCR)}

The prepared cartilage-bone specimens were then washed with physiological saline solution to remove residual bone debris before being subjected to standardized radiography $(25 \mathrm{kV}, 3.8 \mathrm{mAs}$, film focus distance of $8 \mathrm{~cm}$ ) using a high-resolution digital radiography device (Faxitron X-Ray, Illinois, USA). Calcifications were detected as radiopaque spots within the cartilage matrix. Subsequently, the radiographs were qualitatively and quantitatively analysed using standard software (Image J 1.46, National Institutes of Health, Bethesda, USA) $[9,23]$. The amount of calcification was determined as the percentage of the total area of the hyaline cartilage.

\section{Histology}

The histological OA grade was evaluated for the talar and distal tibial cartilage (central load-bearing zone) of all ankle joints. Therefore, a sample of full thickness hyaline cartilage of the previously extracted cartilage-bone-specimen was cut to the subchondral bone plate. All cartilage samples were fixed in $4 \%$ PFA for $24 \mathrm{~h}$ before being dehydrated using $80 \%$ alcohol and embedded in paraffin. Four- $\mu \mathrm{m} \mathrm{sec-}$ tions of all samples were stained with $1 \%$ Safranin-O (Fig. 2) in order to evaluate the samples' histological degeneration grade as it relates to the OARSI osteoarthritis cartilage histopathology assessment system (Grades 0 to 6) [24]. To confirm the occurrence of calcium phosphate deposition, von Kossa staining was performed.

\section{Statistical analysis}

The biometric characteristics of donors are reported as mean values \pm standard deviations. For descriptive analysis, mean CC values for each joint were used. Logarithmic transformation was performed for further

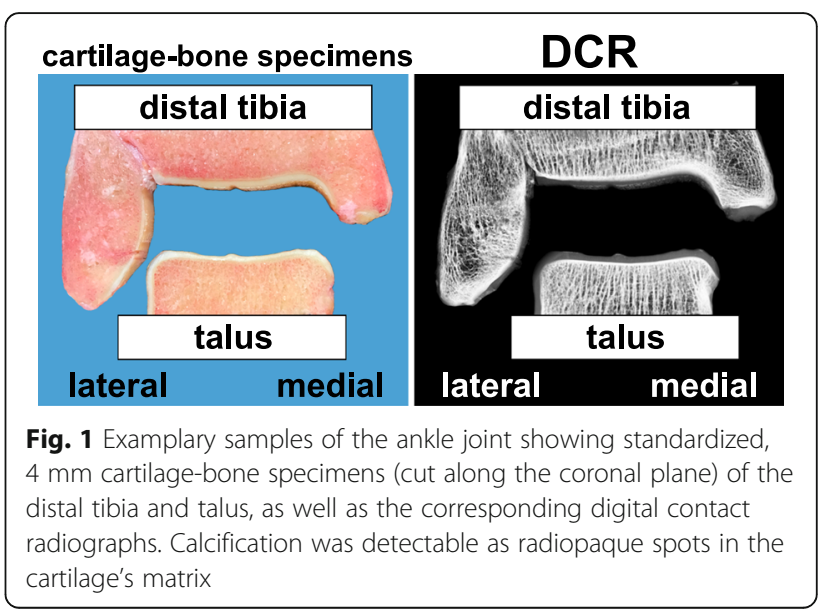




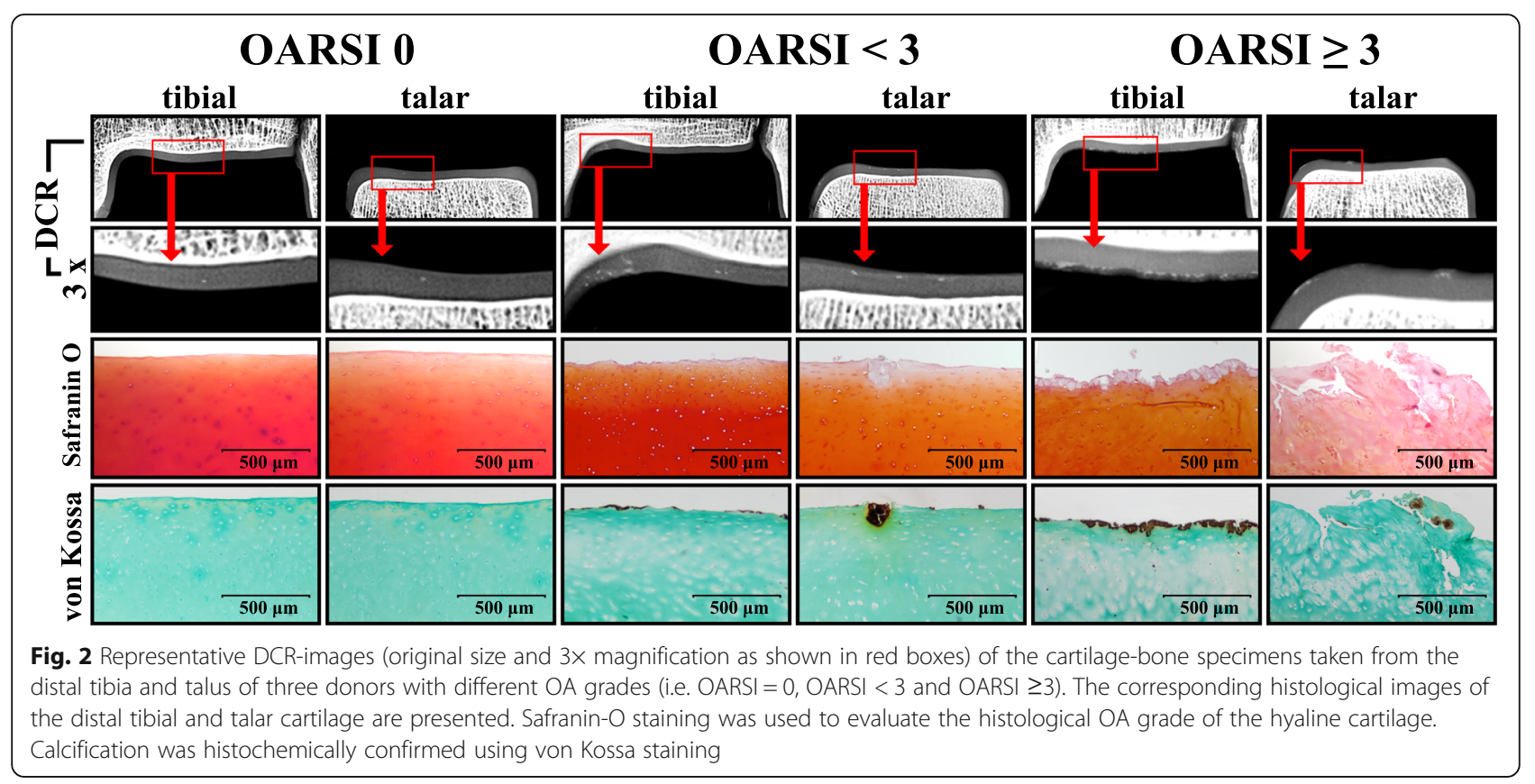

evaluation. Fisher's test was conducted to obtain categorical data, whereas side comparisons were evaluated using McNemar's Exact test. Differences between the mean amount of distal tibial and talar CC were analysed using a linear mixed model. The model takes into account the values of a donor's left and right ankle joints and uses them as random effects with compound symmetry covariance structure (as opposed to using the joint as a fixed effect). In addition, assumptions for the mixed model were checked using residual plots. To determine the association between continuous variables Pearson's $(\mathrm{r})$ or Spearman's $\left(\mathrm{r}_{\mathrm{s}}\right)$ rank correlation coefficient was calculated. Partial correlation calculations were carried out using the respective parameters (CC, histological degeneration grade and age) adjusted to avoid spurious correlations. All statistical analyses were performed with Software R, Version 3.1.1. [25]. P-values of less than 0.05 were considered statistically significant.

\section{Results}

The mean age of the study population was 62.4 years ( $\mathrm{SD} \pm 17.7$, range 23-95 years). Thirty-four of the donors were female, whereas 46 were male. Biometric characteristics of the study population are presented in Table 1.

\section{Prevalence of cartilage calcification}

In our study population, the prevalence of $\mathrm{AJ} C \mathrm{C}$ was $51.3 \%(41 / 80)(95 \%$ CI $[0.40,0.63])$. The left joint was affected in $37.5 \%(30 / 80)$ (95\% CI [0.27, 0.49]) while the right joint in $40.0 \%(32 / 80)(95 \% \mathrm{CI}[0.29,0.52])$ of all cases. No side showed signs of higher susceptibility to CC $(p=0.82)$. Bilateral CC was detected in $26.3 \%$ of donors (21/80). The prevalence of talar CC was $47.5 \%$ (38/80) (95\% CI $[0.36,0.59])$, whereas CC of the distal tibia was $35.0 \%(28 / 80)(95 \%$ CI $[0.25,0.47])$. Bilateral talar CC was noted in $17.5 \%(14 / 80)$, while bilateral CC of the distal tibia was seen in only $8.8 \%(7 / 80)$ of all cases (Table 2).

\section{Gender}

AJ CC was detected in 58.7\% (27/46) (95\% CI [0.43, 0.73]), talar CC in 52.2\% (24/46) (95\% CI [0.37, 0.67]) and distal tibial CC in $39.1 \%(18 / 46)$ (95\% CI [0.25, 0.55]) of all male donors. In the female donor cohort AJ CC was observed in $41.2 \%(14 / 34)(95 \%$ CI [0.25, 0.59]), talar CC in $41.2 \%(14 / 34)$ (95\% CI $[0.25,0.59])$ and distal tibial CC in $29.4 \%(10 / 34)$ (95\% CI [0.15, 0.47]) (Table 2). There were no significant differences regarding the prevalence of AJ CC $(p=0.18)$, talar CC $(p=0.37)$ or distal tibial CC $(p=0.48)$ for gender.

Table 1 Biometric characteristics of the study population $(n=80)$

\begin{tabular}{lc}
\hline Age [years] & $62.4 \pm 17.7$ \\
Male & $59.2 \pm 17.9$ \\
Female & $66.6 \pm 16.7$ \\
Height $[\mathrm{cm}]$ & \\
$\quad$ Male & $177.5 \pm 7.1$ \\
Female & $161.7 \pm 7.9$ \\
Body weight $[\mathrm{kg}]$ & \\
$\quad$ Male & $81.9 \pm 17.9$ \\
Female & $72.3 \pm 11.5$ \\
Body Mass Index $\left[\mathrm{kg} / \mathrm{m}^{2}\right]$ & $25.4 \pm 4.9$ \\
\hline
\end{tabular}


Table 2 Prevalence of DCR-detectable cartilage calcification $(n=80)$

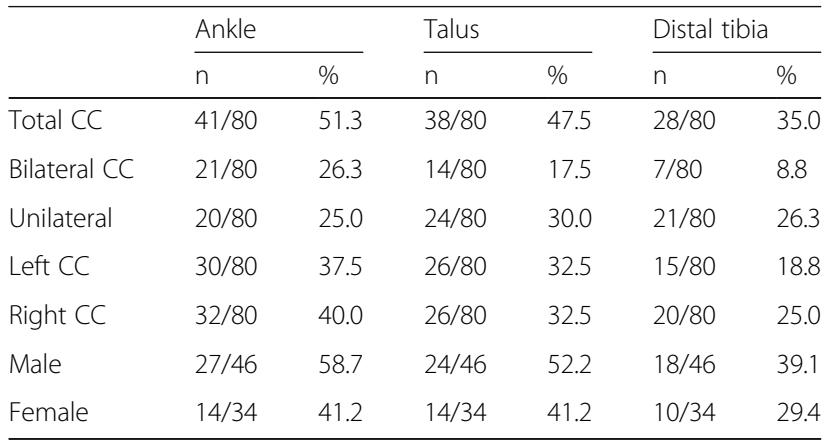

\section{Quantitative analysis of cartilage calcification}

The mean amount of AJ CC was quantitated at $0.17 \%$ ( $\mathrm{SD} \pm 0.52$, range: $0.00-3.55$ ); left AJ CC 0.22\% (SD \pm 0.77, range: $0.00-5.97$ ) and right $\mathrm{AJ} \mathrm{CC} 0.13 \%$ (SD \pm 0.41 , range: $0.00-3.03)$. Significant correlations were noted between the two joints $(r=0.52, p=0.02)$ (Fig. 3a).

The mean amount of talar CC was quantified at $0.15 \%$ ( $\mathrm{SD} \pm 0.43$, range: $0.00-3.04)$ and distal tibia $\mathrm{CC}$ at $0.39 \%$ (SD \pm 1.53 , range: $0.00-11.53$ ). Significant correlations were found between the mean amount of CC noted in the talar and distal tibial cartilage $(r=0.59$, $p=0.002$ ) (Fig. 3b), however, no quantitative differences could be detected ( $p=0.06)$ (Fig. 3c).

\section{Cartilage degeneration (OARSI score)}

The mean histological degeneration grade of the left/ right distal tibia was $1.5(\mathrm{SD} \pm 1.0$, range: $0-5) / 1.5(\mathrm{SD} \pm$ 1.0, range: $0-6)$ and of the left/right talus 1.3 ( $\mathrm{SD} \pm 1.1$, range: $0-6) / 1.6(\mathrm{SD} \pm 1.1$, range: $0-5)$. The distribution of the histological OA grade according to the OARSI score system (Grade 0-6) is presented in Table 3.

\section{Cartilage calcification and histological degeneration Distal tibial cartilage}

Distal tibial CC was detected in only $11.9 \%(17 / 143)$ of the cases that were classified as 'mild cartilage damage' (OARSI <3). However, distal tibial CC was reported in $82.4 \%(14 / 17)$ of the cases with 'severe cartilage degeneration' (OARSI $\geq 3$ ), (Table 4). Quantitative analysis revealed significant correlations between the mean amount of distal tibial $\mathrm{CC}$ and the histological degeneration, both without $(r=0.70, p<0.001,95 \% \mathrm{CI}$ $[0.44,0.85])$ and after an adjustment for age $(r=0.68$, $p<0.001$ ) (Fig. 4a). Conversely, there was no significant correlation between the amount of distal tibial CC and the histological degeneration of the talus $(r=0.23, p=0.25)$.

\section{Talar cartilage}

Talar CC was detected in only $21.5 \%(29 / 135)$ of the cases with 'mild cartilage damage' (OARSI $<3$ ) and in 92.0\% (23/25) of the cases with 'severe cartilage degeneration' (OARSI $\geq 3$ ) (Table 4). Overall, a significant correlation was observed between the amount of talar CC and the histological degeneration grade of the talus, both without $(r=0.72, p<0.001,95 \% \mathrm{CI}[0.52,0.85])$ and after an adjustment for age was conducted $(r=0.72$, $p<0.001$ ) (Fig. 4b). Additionally, significant correlations were noted between the amount of talar CC and distal tibial degeneration $(r=0.61, p<0.001,95 \%$ CI $[0.36,0.78])$.

\section{Cartilage calcification and age \\ Distal tibial cartilage}

No correlation was observed between the amount of distal tibial CC and age without $(p=0.32)$ and after an adjustment for histological degeneration grade $(p=0.75)$ (Fig. 4c).
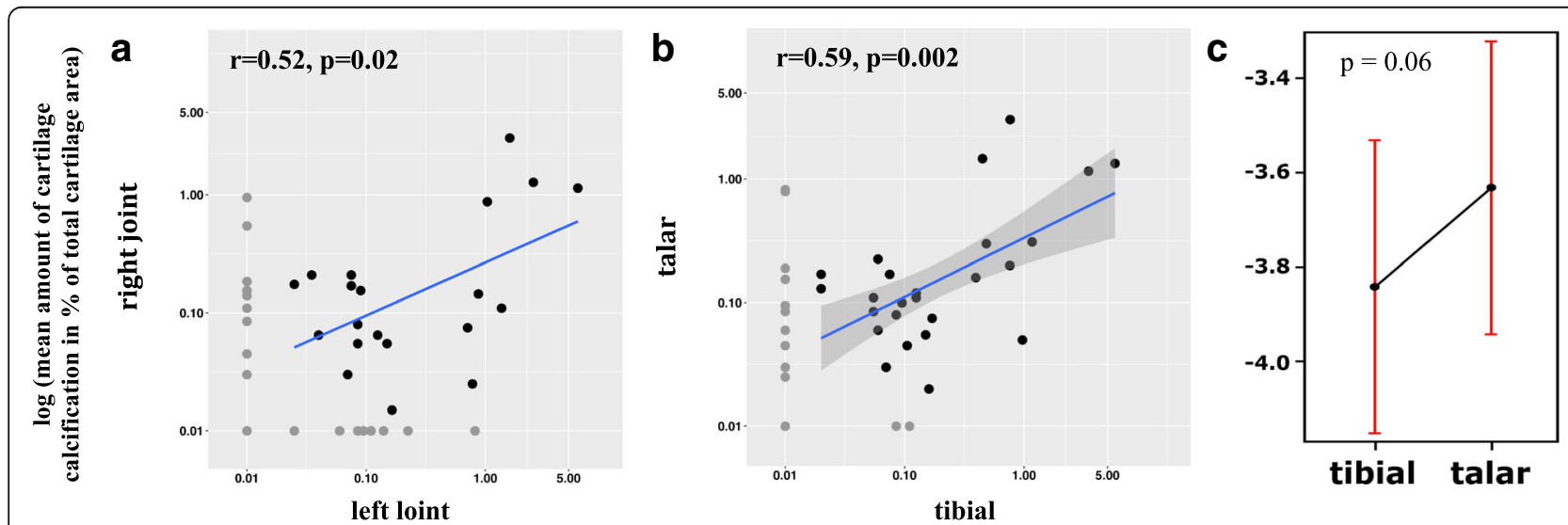

Fig. 3 a, b. Logarithmic scatter plots (with blue orthogonal regression lines) showing significant correlations between the mean amount of CC in (a) the right and left ankle joints and (b) between the talar and distal tibial cartilage. Data points have been adjusted to avoid over-plotting. $\mathbf{c}$ The mean amount of calcification in the distal tibial and talar cartilage is depicted as an Effect Plot (logarithmic) 
Table 3 Distribution of the histological OA-grade by OARSI $(n=80)$

\begin{tabular}{|c|c|c|c|c|c|c|c|c|}
\hline \multirow[b]{3}{*}{ OARSI } & \multicolumn{4}{|c|}{$\underline{\text { Distal tibia }}$} & \multicolumn{4}{|c|}{ Talus } \\
\hline & \multicolumn{2}{|c|}{ Left } & \multicolumn{2}{|c|}{ Right } & \multicolumn{2}{|c|}{ Left } & \multicolumn{2}{|c|}{ Right } \\
\hline & $n$ & $\%$ & $n$ & $\%$ & $n$ & $\%$ & $n$ & $\%$ \\
\hline 0 & 9 & 11.3 & 12 & 15.0 & 18 & 22.5 & 12 & 15.0 \\
\hline 1 & 37 & 46.3 & 33 & 41.3 & 35 & 43.8 & 32 & 40.0 \\
\hline 2 & 26 & 32.5 & 26 & 32.5 & 17 & 21.3 & 21 & 26.3 \\
\hline 3 & 5 & 6.3 & 7 & 8.8 & 6 & 7.5 & 11 & 13.8 \\
\hline 4 & 1 & 1.3 & 1 & 1.3 & 3 & 3.8 & 3 & 3.8 \\
\hline 5 & 2 & 2.5 & 0 & 0.0 & 0 & 0.0 & 1 & 1.3 \\
\hline 6 & 0 & 0.0 & 1 & 1.3 & 1 & 1.3 & 0 & 0.0 \\
\hline
\end{tabular}

\section{Talar cartilage}

There was no correlation between the amount of talar $\mathrm{CC}$ and age without $(p=0.49)$ and after an adjustment for histological degeneration grade $(p=0.30)$ (Fig. $4 \mathrm{~d})$.

\section{Cartilage calcification and BMI}

No correlation was detected between the amount of $\mathrm{CC}$ and the BMI of the donor for both the distal tibial $(p=0.51)$ and the talar cartilages $(p=0.87)$.

\section{Histological degeneration grade and age}

Correlations were noted between the histological degeneration grade of the distal tibial/talar hyaline cartilage and age $((r=0.28, p=0.01,95 \%$ CI $[0.06,0.47]) /(r=0.40$, $p<0.001,95 \%$ CI $[0.20,0.57]))$.

\section{Discussion}

Independent of the donor's gender and side, an unexpectedly high prevalence of AJ CC (51.3\%) was found in this study. Intraindividual correlations existed between the amount of $\mathrm{CC}$ of the left with that of the right AJ, as well as between the distal tibial and the talar cartilage. These findings underline the systemic appearance of ankle-related CC. Furthermore, since calcification has already been found in intact AJ cartilage and the amount of $\mathrm{CC}$ correlated with the histological OA grade, we hypothesize that $\mathrm{CC}$ may play a causative role in the pathogenesis of AJ OA.

So far, the prevalence of ankle-related $\mathrm{CC}$ has been reported in only one cross-sectional study [20]. However, since calcium phosphate deposition is known to begin in

Table 4 Distribution of joints with mild (OARSI < 3) and severe (OARSI $\geq 3)$ OA-grade with positive CC $(n=160)$

\begin{tabular}{llllll}
\hline & \multicolumn{2}{l}{ Distal tibia } & & \multicolumn{2}{l}{ Talus } \\
\cline { 2 - 3 } OARSI & $\mathrm{n}$ & & $\mathrm{n}$ & $\%$ \\
\hline$<3$ & $17 / 143$ & 11.9 & & $29 / 135$ & 21.5 \\
\hline 3 & $14 / 17$ & 82.4 & & $23 / 25$ & 92.0 \\
\hline
\end{tabular}

the nano- to micrometre range, it is almost impossible to detect the early stages of calcification through macroscopic analysis or even using standard radiographic techniques. High-resolution imaging techniques such as Digital Contact Radiography (DCR) are therefore necessary for detection of the onset of CC [21]. Using DCR, we were able to establish that CC was prevalent in $51.3 \%$ of all cases; this was in stark contrast to previously published studies in which the prevalence of CC was a mere $4.7 \%$ [20]. Despite this, DCR has shown that AJ $\mathrm{CC}$ is relatively rare when compared to the prevalence of CC in other joints, such as the shoulder (98.9\%) [26], the hip (96.6\%) [11] or the knee (94.3-100\%) [11, 23]. Nonetheless, the reason for the difference remains elusive. Interestingly, calcification is comparably prevalent in both the AJ and the MTP-I joint (48.1\%) [12]. It has been theorized that weight-loading promotes pro-mineralization of the joints $[27,28]$, however, the results of our study contradict this point. Since the ankle generally bears enormous loads (many times greater than body weight), it stands to reason that the degree of calcification should be higher. Moreover, other studies have reported that calcification is more prevalent in non-weight bearing joints such as the shoulder [26] and has even been observed in non-weight-bearing parts of the knee cartilage [29]. Another factor to investigate is the impact of the donor's BMI on CC (additional mechanical stress induced by increasing BMI). We could not find any association between the donor's BMI and the mean amount of AJ CC. Given this, it can be assumed that mechanical load is not the predominant factor.

Our study highlighted significant correlations between the mean amount of $\mathrm{CC}$ in the left and right $\mathrm{AJ}$, between the left and right distal tibia and talus, as well as correlations between the mean amount of calcification in the distal tibial and talar cartilage. These results underline the theory that the development of calcification is systemic $[11,26,30]$.

Another interesting observation was the correlation between $\mathrm{CC}$ and the donor's histological OA grade. CC was detected in donors with histologically intact or almost intact hyaline cartilage (i.e. an OARSI grade $<3$ ) in $12 \%$ and in $22 \%$ of the distal tibial and talar cartilage respectively. Given this, it can be indicated that $\mathrm{CC}$ is already present in the joint before the histological OA is even measurable, and might occur before the OA process initiates. Similar observations of spontaneous OA development have been found in two animal models $[31,32]$, wherein calcification was detectable before cartilage degeneration occurred.

In comparison with other joints [9-13, 26, 30, 33], there is also a clear association between $\mathrm{CC}$ and OA in the ankle. In our study, $\mathrm{CC}$ in the distal tibia was detectable in $82 \%$ of the donors with severe OA (i.e. an OARSI 


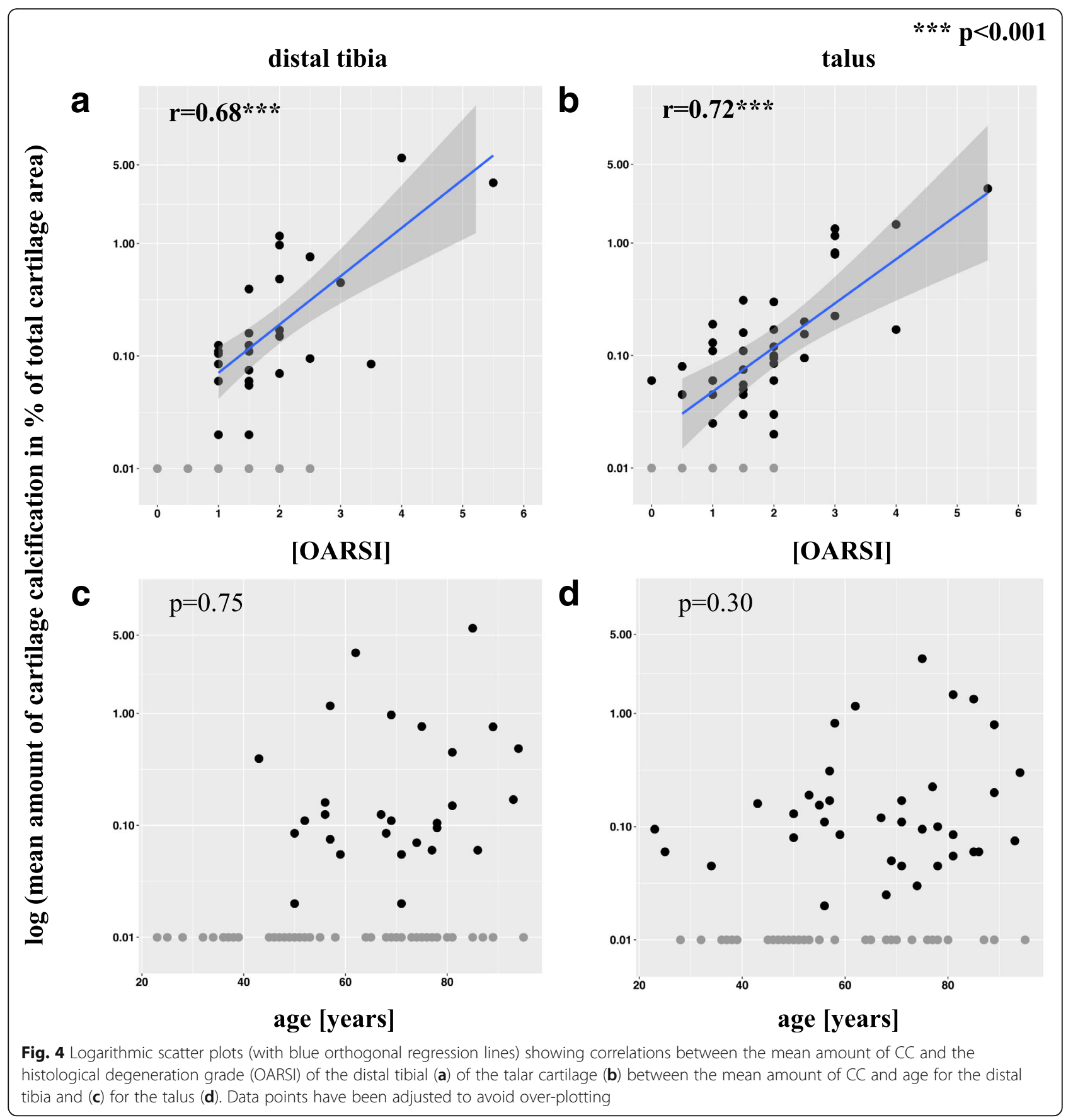

grade $\geq 3$ ), whereas talar CC was detected in $92 \%$. Moreover, our quantitative analysis demonstrated that the mean amount of calcification in the distal tibial, as well as in the talar cartilage correlated with the histological degeneration grade. Muehlemann et al. also described an association between the prevalence of $\mathrm{CC}$ and macroscopic talar degeneration, even though no quantitative analysis was conducted for their study [20]. Taken together, there seems to be evidence that $\mathrm{CC}$ plays a crucial role in the development of AJ OA.
No correlation was found between the mean amount of AJ CC and the donors' age. This is in line with previously published results for other joints, including the shoulder [26], the hip/knee [11] and the MTP-I joint [12]. In contrast, Mitsuyama et al. [23] observed significant correlations between the mean amount of $\mathrm{CC}$ in the knee and age of the general population. However, since no adjustment for the donor's OA grade was conducted, it is conceivable that this association between $\mathrm{CC}$ and donor age might have been a spurious 
correlation, which would disappear once an adjustment for OA grade would be performed.

Certainly, there are some limitations to this study. There were no information about the donor lifestyle, activity and medical history, in particular ankle complaints. Even though the standardized cartilage-bone specimens of the distal tibia and talus used in this study were representative, they reflected only a small proportion of the ankle articulating surface. Lastly, the calcium-phosphate composition of DCR-detected CC was not thoroughly characterized in our study since such analyses require the use of specific diagnostic methods, e.g. FTIR spectroscopy [34] or X-Ray diffractometry [35], and were not specifically in the scope of our study. Nevertheless, none of these limitations is likely to influence the study's findings and conclusions.

\section{Conclusion}

DCR analysis revealed that the prevalence of ankle-related cartilage calcification is much higher than previously considered in general population. Even though it is independent of the donor's age and/or BMI, calcification seems to occur in histologically intact ankle cartilage and is linked with the joint's histological OA grade. These insights indicate that hyaline $\mathrm{CC}$ is an early, age-independent element and a possible causative factor in the development of ankle-related osteoarthritis. However, the exact pathophysiological role of CC in osteoarthritis and its subsequent importance in the disease's molecular mechanisms are yet to be identified and investigated.

\section{Abbreviations \\ AJ: Ankle joint; CC: Cartilage calcification; DCR: Digital-contact radiography; OA: Osteoarthritis; OARSI: Osteoarthritis cartilage histopathology assessment system}

\section{Acknowledgements}

We would like to thank Shahed Taheri for proofreading the manuscript and Elke Leicht of the Department of Osteology and Biomechanics, University Medical Centre Hamburg-Eppendorf for providing expert technical assistance throughout this project.

\section{Availability of data and materials}

All data generated or analysed in this study is available on request from the corresponding authors.

\section{Authors' contributions}

$\mathrm{JH}$ and $\mathrm{TH}$ contributed equally to the conception and design of the study, the acquisition analysis and interpretation of data, as well as to the creation and revision of the manuscript. SH and AU was responsible for conducting statistical analysis and interpreting the data. LW, TR, TS, and SKB conducted both DCR and histological analysis; they also contributed equally to the interpretation of the data. KP was responsible for data acquisition. WL and FTB conducted data interpretation and contributed equally to drafting and revising the manuscript. All authors have read and approved the final manuscript. All authors included on this paper have made substantial contributions to this work and have fulfilled the criteria for authorship. Both Jan Hubert (jan.hubert@med.uni-goettingen.de) and Thelonius Hawellek (thelonius.hawellek@med.uni-goettingen.de) take full responsibility for the integrity of this study from inception to completion.

\section{Ethics approval and consent to participate}

This cross-sectional study was approved by the Ethics Committee of the Medical Association Hamburg, Germany (Ärztekammer Hamburg, PV 4570), and was carried out in accordance with existing regulations set by the University Medical Center Hamburg-Eppendorf. Written informed consent for the removal and use of joints for scientific purposes was obtained from the family members.

\section{Competing interests}

All authors have disclosed all financial and personal relationships that could potentially and inappropriately influence this work. The authors declare that they have no competing interests.

\section{Publisher's Note}

Springer Nature remains neutral with regard to jurisdictional claims in published maps and institutional affiliations.

\section{Author details}

'Department of Trauma Surgery, Orthopaedics and Plastic Surgery, University Medical Center Göttingen, Robert-Koch-Straße 40, 37075 Göttingen, Germany. ${ }^{2}$ Department of Medical Biometry and Epidemiology, University Medical Center Hamburg-Eppendorf, Hamburg, Germany. ${ }^{3}$ Department of Urology, University Medical Center Göttingen, Göttingen, Germany. ${ }^{4}$ Department of Osteology and Biomechanics, University Medical Center Hamburg-Eppendorf, Hamburg, Germany. ${ }^{5}$ Department of Legal Medicine, University Medical Center Hamburg-Eppendorf, Hamburg, Germany.

Received: 3 January 2018 Accepted: 16 May 2018

Published online: 24 May 2018

\section{References}

1. Felson DT. The epidemiology of osteoarthritis: prevalence and risk factors. In: Kuettner KE, Goldberg VM, editors. Osteoarthritis Disorders. Rosemont, IL: American Academy Orthopedic Surgeons; 1995. p. 13e24.

2. Peyron JG. The epidemiology of osteoarthritis. In: Moskowitz RW, Howell DS, Goldberg VM, Mankin HJ, editors. Osteoarthritis. Diagnosis and Treatment. Philadelphia, PA: WB Saunders; 1984. p. 9-27.

3. Saltzman $\mathrm{CL}$, Salamon ML, Blanchard GM, et al. Epidemiology of ankle arthritis: report of a consecutive series of 639 patients from a tertiary orthopaedic center. lowa Orthop J. 2005;25:44-6.

4. Valderrabano V, Horisberger M, Russell I, et al. Etiology of ankle osteoarthritis. Clin Orthop Relat Res. 2009;467(7):1800-6.

5. Lindsjö U. Operative treatment of ankle fracture-dislocations: a follow-up study of 306/321 consecutive cases. Clin Orthop Relat Res. 1985;199:28-38.

6. Eckstein F, Winzheimer M, Hohe J, et al. Interindividual variability and correlation among morphological parameters of knee joint cartilage plates: analysis with three-dimensional MR imaging. Osteoarthr Cartil. 2001;9(2):101-11.

7. Quinn TM, Häuselmann HJ, Shintani N, Hunziker EB. Cell and matrix morphology in articular cartilage from adult human knee and ankle joints suggests depth-associated adaptations to biomechanical and anatomical roles. Osteoarthr Cartil. 2013;21(12):1904-12.

8. Zhang W, Doherty $M$, Bardin T, et al. European league against rheumatism recommendations for calcium pyrophosphate deposition. Part I: terminology and diagnosis. Ann Rheum Dis. 2011;70(4):563-70.

9. Fuerst M, Bertrand J, Lammers $\mathrm{L}$, et al. Calcification of articular cartilage in human osteoarthritis. Arthritis Rheum. 2009;60(9):2694-703.

10. Fuerst $M$, Niggemeyer $O$, Lammers $L$, et al. Articular cartilage mineralization in osteoarthritis of the hip. BMC Musculoskelet Disord. 2009;10:166. https:// doi.org/10.1186/1471-2474-10-166.

11. Hawellek T, Hubert J, Hischke S, et al. Articular cartilage calcification of the hip and knee is highly prevalent, independent of age but associated with histological osteoarthritis: evidence for a systemic disorder. Osteoarthr Cartil. 2016;24(12):2092-9. https://doi.org/10.1016/j.joca.2016.06.020. Epub 2016 Jul 5

12. Hubert J, Hawellek T, Hischke $S$, et al. Hyaline cartilage calcification of the first metatarsophalangeal joint is associated with osteoarthritis but independent of age and BMI. BMC Musculoskelet Disord. 2016;17(1):474

13. Neame RL, Carr AJ, Muir K, et al. UK community prevalence of knee chondrocalcinosis: evidence that correlation with osteoarthritis is through a shared association with osteophyte. Ann Rheum Dis. 2003;62(6):513-8. 
14. Roemhildt ML, Beynnon BD, Gardner-Morse M. Mineralization of articular cartilage in the Sprague-Dawley rat: characterization and mechanical analysis. Osteoarthr Cartil. 2012;20(7):796-800.

15. Roemhildt ML, Gardner-Morse MG, Morgan CF, et al. Calcium phosphate particulates increase friction in the rat knee joint. Osteoarthr Cartil. 2014; 22(5):706-9.

16. McCarthy GM, Westfall PR, Masuda I, Christopherson PA, Cheung HS, Mitchell PG. Basic calcium phosphate crystals activate human osteoarthritic synovial fibroblasts and induce matrix metalloproteinase-13 (collagenase-3) in adult porcine articular chondrocytes. Ann Rheum Dis. 2001;60(4):399-406.

17. Morgan MP, Whelan LC, Sallis JD, et al. Basic calcium phosphate crystalinduced prostaglandin E2 production in human fibroblasts: role of cyclooxygenase 1, cyclooxygenase 2, and interleukin-1 beta. Arthritis Rheum. 2004;50(5):1642-9.

18. Ea HK, Uzan B, Rey C, Lioté F. Octacalcium phosphate crystals directly stimulate expression of inducible nitric oxide synthase through p38 and JNK mitogen-activated protein kinases in articular chondrocytes. Arthritis Res Ther. 2005;7(5):R915-26.

19. Nasi S, So A, Combes C, et al. Interleukin-6 and chondrocyte mineralisation act in tandem to promote experimental osteoarthritis. Ann Rheum Dis. 2015. pii: annrheumdis-2015-207487. doi: https://doi.org/10.1136/ annrheumdis-2015-207487. [Epub ahead of print].

20. Muehleman C, Li J, Aigner T, et al. Association between crystals and cartilage degeneration in the ankle. J Rheumatol. 2008;35(6):1108-17. Epub 2008 Apr 15

21. Abreu M, Johnson K, Chung CB, et al. Calcification in calcium pyrophosphate dihydrate (CPPD) crystalline deposits in the knee: anatomic, radiographic, MR imaging, and histologic study in cadavers. Skelet Radiol. 2004;33(7):392-8. Epub 2004 May 11

22. Püschel K. Teaching and research on corpses. Mortui vivos docent. Rechtsmedizin. 2016;26(2):115-9.

23. Mitsuyama H, Healey RM, Terkeltaub RA, et al. Calcification of human articular knee cartilage is primarily an effect of aging rather than osteoarthritis. Osteoarthr Cartil. 2007;15(5):559-65.

24. Pritzker KP, Gay S, Jimenez SA, et al. Osteoarthritis cartilage histopathology: grading and staging. Osteoarthr Cartil. 2006;14(1):13-29.

25. Team RC. R: A language and environment for statistical computing. Vienna: R Foundation for Statistical Computing; 2014. URL http://www.R-project.org

26. Hawellek T, Hubert J, Hischke $\mathrm{S}$, et al. Articular cartilage calcification of the humeral head is highly prevalent and associated with osteoarthritis in the general population. J Orthop Res. 2016;34(11):1984-90. https://doi.org/10. 1002/jor.23227. Epub 2016 Apr 6

27. Carlson AK, McCutchen CN, June RK. Mechanobiological implications of articular cartilage crystals. Curr Opin Rheumatol. 2017;29(2):157-62.

28. Taylor AM. Metabolic and endocrine diseases, cartilage calcification and arthritis. Curr Opin Rheumatol. 2013;25(2):198-203.

29. Nguyen C, Bazin D, Daudon M, et al. Revisiting spatial distribution and biochemical composition of calcium-containing crystals in human osteoarthritic articular cartilage. Arthritis Res Ther. 2013;15(5):R103.

30. Abhishek A, Doherty S, Maciewicz R, et al. Evidence of a systemic predisposition to chondrocalcinosis and association between chondrocalcinosis and osteoarthritis at distant joints: a cross-sectional study. Arthritis Care Res (Hoboken). 2013;65(7):1052e8.

31. Bendele AM, White SL. Early histopathologic and ultrastructural alterations in femorotibial joints of partial medial meniscectomized Guinea pigs. Vet Pathol. 1987;24(5):436-43.

32. Evans RG, Collins C, Miller P, et al. Radiological scoring of osteoarthritis progression in STR/ORT mice. Osteoarthr Cartil. 1994;2(2):103-9.

33. Hawellek T, Hubert J, Hischke S, et al. Microcalcification of lumbar spine intervertebral discs and facet joints is associated with cartilage degeneration, but differs in prevalence and its relation to age. J Orthop Res. 2017:35(12):2692-9.

34. Dessombz A, Nguyen C, Ea HK, et al. Combining $\mu X$-ray fluorescence, $\mu X A N E S$ and $\mu$ XRD to shed light on Zn2+ cations in cartilage and meniscus calcifications. J Trace Elem Med Biol. 2013;27(4):326-33.

35. Nguyen C, Ea HK, Thiaudiere D, et al. Calcifications in human osteoarthritic articular cartilage: ex vivo assessment of calcium compounds using XANES spectroscopy. J Synchrotron Radiat. 2011;18(Pt 3):475-80.

\section{Ready to submit your research? Choose BMC and benefit from:}

- fast, convenient online submission

- thorough peer review by experienced researchers in your field

- rapid publication on acceptance

- support for research data, including large and complex data types

- gold Open Access which fosters wider collaboration and increased citations

- maximum visibility for your research: over $100 \mathrm{M}$ website views per year

At BMC, research is always in progress.

Learn more biomedcentral.com/submissions 